\title{
Quantitative whole-heart three-dimensional magnetic resonance myocardial perfusion imaging in systole and diastole at 3.0T
}

\author{
Manish Motwani ${ }^{1 *}$, Ananth Kidambi ${ }^{1}$, Timothy Fairbairn', Akhlaque Uddin', Sebastian Kozerke², Steven Sourbron ${ }^{3}$, \\ John P Greenwood ${ }^{1}$, Sven Plein ${ }^{1}$ \\ From 16th Annual SCMR Scientific Sessions \\ San Francisco, CA, USA. 31 January - 3 February 2013
}

\section{Background}

Two-dimensional (2D) perfusion-CMR has been shown to have greater diagnostic accuracy than single-photon emission computed tomography but remains limited by a lack of complete myocardial coverage. Three-dimensional (3D) whole-heart myocardial perfusion CMR addresses this limitation and has recently been shown to be clinically feasible. However, the feasibility and potential clinical utility of quantitative 3D perfusion measurements, as already shown with 2D-perfusion-CMR and positron emission tomography, has yet to be evaluated. The purpose of this study was to establish the feasibility of quantitative 3Dperfusion-CMR to detect coronary artery disease (CAD). Additionally, as 3D-perfusion-CMR offers the opportunity to select the phase of acquisition, a secondary objective was to determine differences between systolic and diastolic estimates of myocardial blood flow (MBF).

\section{Methods}

35 patients underwent 3D-perfusion-CMR (Philips 3T Achieva TX) with data acquired at both end-systole and mid-diastole (Fig 1). Systolic and diastolic perfusion images were analyzed in separate reporting sessions in random order. Image quality $(0=$ non-diagnostic, $1=$ poor, $2=$ adequate and $3=$ excellent) and the occurrence of artifact related to respiratory-motion, $\mathrm{k}-\mathrm{t}$ reconstruction or dark-rim artifact $(0=$ none, $1=$ mild, $2=$ moderate and $3=$ severe) were scored. MBF and myocardial perfusion reserve (MPR) were estimated on a per patient and per territory basis by Fermi function deconvolution. CAD was defined as luminal stenosis $\geq 70 \%$ on quantitative coronary angiography.

\section{Results}

38 coronary territories had significant CAD. MPR had a high diagnostic accuracy for the detection of CAD, in both systole and diastole (area under curve: 0.92 vs. 0.94; $\mathrm{p}=0.41)$ (Fig 2). At rest, systolic and diastolic MBF estimates were similar - in both normal and diseased territories (no CAD: $1.24 \pm 0.15$ vs. $1.25 \pm 0.15 \mathrm{ml} / \mathrm{g} / \mathrm{min}$, $\mathrm{p}=0.27$; CAD: $1.24 \pm 0.15$ vs. $1.26 \pm 0.14 \mathrm{ml} / \mathrm{g} / \mathrm{min}$, $\mathrm{p}=0.20$ ). At stress, diastolic MBF estimates were significantly greater than systolic estimates (no CAD: $3.21 \pm 0.50$ vs. $2.75 \pm 0.42 \mathrm{ml} / \mathrm{g} / \mathrm{min}, \mathrm{p}<0.0001$; CAD: $2.13 \pm 0.45$ vs. $1.98 \pm 0.41 \mathrm{ml} / \mathrm{g} / \mathrm{min}, \mathrm{p}<0.0001)$. The diastolic/systolic stress MBF ratio was significantly reduced in territories with CAD (CAD: $1.08 \pm 0.06$ vs. no CAD: $1.17 \pm 0.11$; $\mathrm{p}<0.0001)$. Systolic acquisition had a higher overall image quality score (median: 3 vs. $2, \mathrm{p}=0.002$ ) and was less prone to artifact than diastolic acquisition (median artifact score: 0 vs. $1 ; \mathrm{p}<0.0001)$. In particular, there was a greater frequency of dark-rim artifact in diastole compared to systole (19 vs. 9 patients).

\section{Conclusions}

We have shown that quantitative 3D-perfusion-CMR is feasible and can be used to detect CAD with high diagnostic accuracy. Image quality and less artifact, make systole the

${ }^{1}$ MCRC \& LIGHT, University of Leeds, Leeds, UK

Full list of author information is available at the end of the article

(c) 2013 Motwani et al; licensee BioMed Central Ltd. This is an Open Access article distributed under the terms of the Creative 


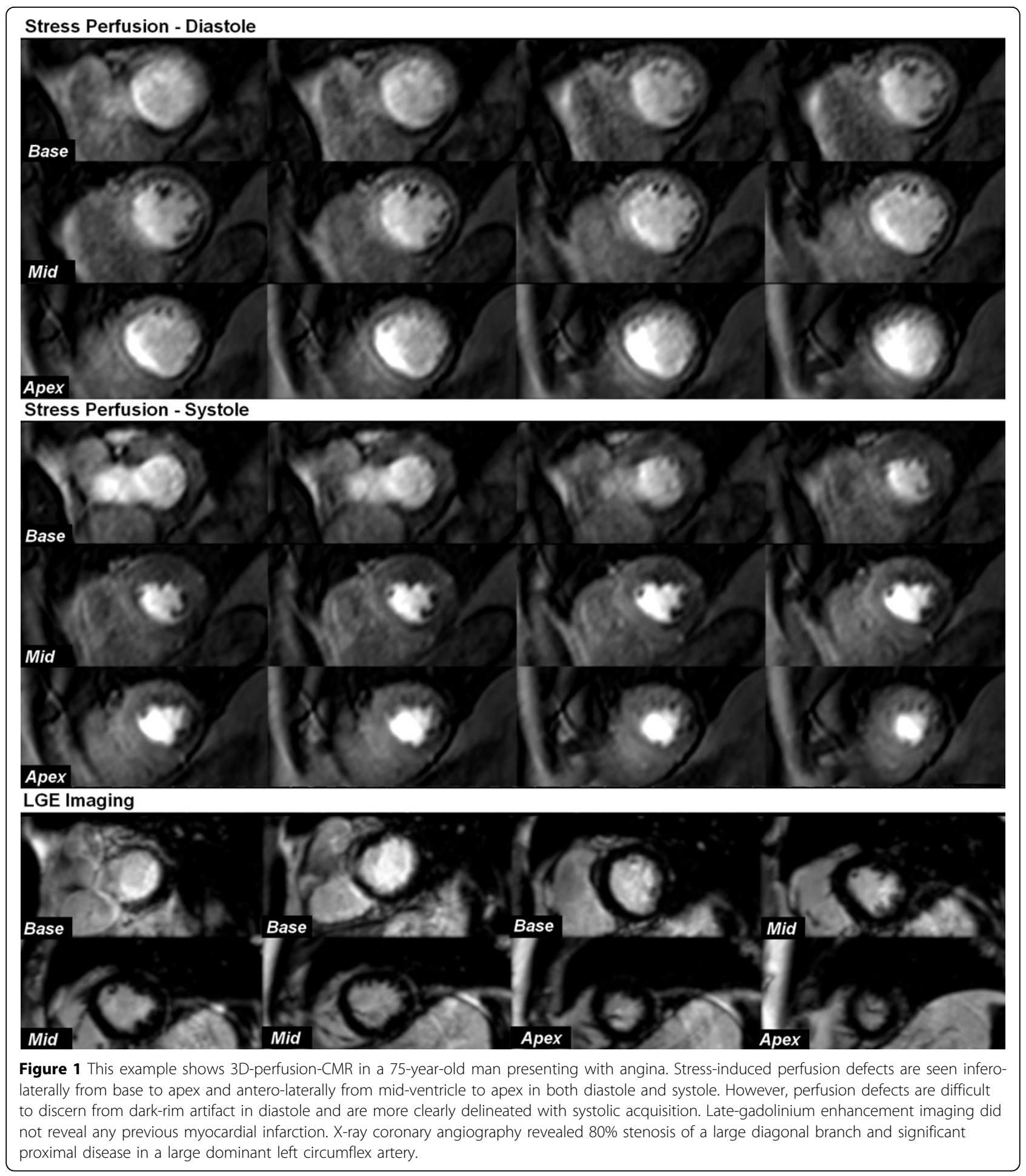

preferred phase for acquisition in 3D-perfusion-CMR. Finally, there were significant differences in systolic and diastolic MBF estimates and therefore the phase of acquisition should always be stated in future quantitative studies.

\section{Funding}

JPG and SP receive an educational research grant from Philips Healthcare. SP is funded by a BHF fellowship (FS/1062/28409). 


\section{Systole}

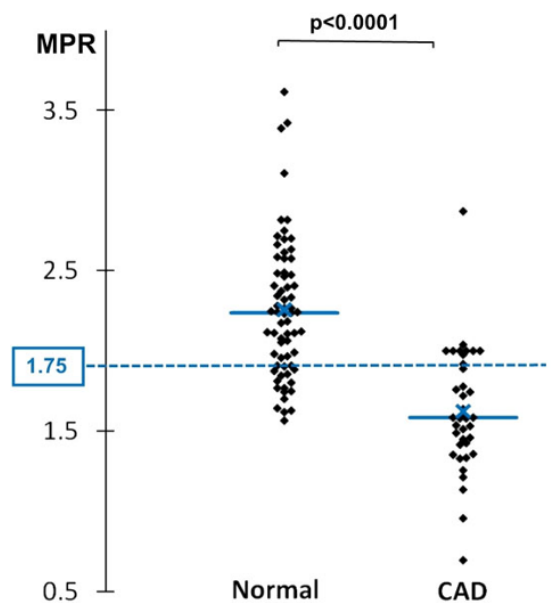

\section{Diastole}

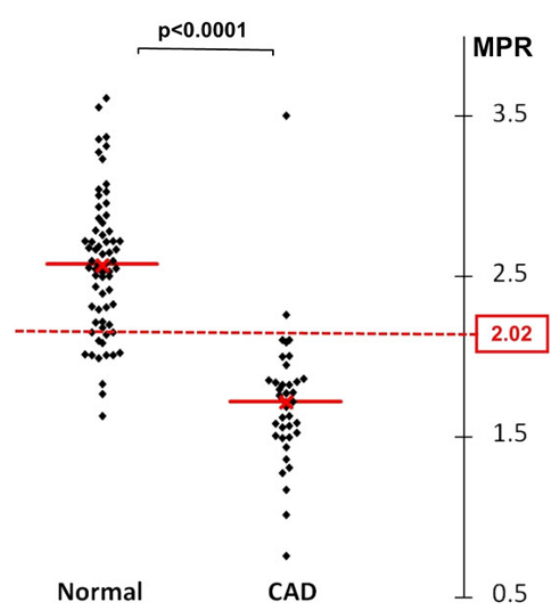

Figure 2 These charts show the individual myocardial perfusion reserve (MPR) values from normal and significantly diseased perfusion territories with both systolic and diastolic acquisition ( $x=$ mean value, solid line = median value). The optimal cut-off MPR values determined by receiveroperating characteristic (ROC) analysis are also plotted (dashed lines, 1.75 for systole and 2.02 for diastole). ROC analysis found MPR had a high diagnostic accuracy for the detection of CAD, in both systole and diastole (area under curve: 0.92 vs. 0.94 respectively; $p=0.41$ ).

\section{Author details}

'MCRC \& LIGHT, University of Leeds, Leeds, UK. Institute for Biomedical Engineering, University and ETH Zurich, Zurich, Switzerland. ${ }^{3}$ Medical Physics,

University of Leeds, Leeds, UK.

Published: 30 January 2013

doi:10.1186/1532-429X-15-S1-P206

Cite this article as: Motwani et al:: Quantitative whole-heart threedimensional magnetic resonance myocardial perfusion imaging in systole and diastole at 3.0T. Journal of Cardiovascular Magnetic Resonance 2013 15(Suppl 1):P206.

Submit your next manuscript to BioMed Central and take full advantage of:

- Convenient online submission

- Thorough peer review

- No space constraints or color figure charges

- Immediate publication on acceptance

- Inclusion in PubMed, CAS, Scopus and Google Scholar

- Research which is freely available for redistribution

Submit your manuscript at www.biomedcentral.com/submit 